\title{
Linha de Pesquisa: Possibilidades de Definição e Tipos de Utilização do Conceito
}

\section{Paulo Rogério Meira Menandro}

A iniciativa da Revista de Administração Contemporânea (RAC) de acolher uma discussão sobre o conceito de linha de pesquisa é extremamente oportuna. Isso fica evidente quando se percebe tratar-se de conceito largamente utilizado em curriculum vitae, em descrição de grupos de pesquisas, na especificação da abrangência de Programas de Pós-Graduação, em documentos oficiais de agências de fomento, destacado como elemento importante a ser considerado no âmbito da avaliação dos Programas de Pós-Graduação, que precisa ser considerado pelos formuladores de novas propostas de novos cursos de pós-graduação, mas que, ainda assim, carece de uma definição, cuja aceitação seja expressivamente compartilhada.

O texto do Professor Jairo Eduardo Borges-Andrade, que devo aqui comentar, é muito esclarecedor e estimulante, ao inventariar e discutir o que ele chamou de “sérios problemas de definição (ou de ausência de definição)”. O texto mencionado inclui, de forma generosa, algumas considerações que fiz sobre o assunto em pauta. Isso torna minha tarefa de escrever uma réplica especial, pois seria impróprio, em tal situação, falar em replicar no sentido de redargüir, de contrapor argumentos. Para não correr o risco de replicar em outro sentido - o de produzir uma cópia - minha alternativa é acrescentar alguns novos pontos, ou novas facetas dos mesmos pontos, na esperança de contribuir para estimular a discussão.

Entre todas as evidências de precariedade de informações sobre o conceito de linha de pesquisa, tal como destacado no texto do Professor Jairo, fica claro que não há sequer informação imediatamente disponível sobre a história de utilização do termo. A criação do nosso sistema de pós-graduação ocorreu em cenário no qual coexistiam dois modelos de pós-graduação: o de inspiração européia, representado pelos doutorados de pesquisa da USP e pelas docências livres; e o de inspiração norte-americana, tal como implantado na COPPE/UFRJ, na UFRGS, no ITA e na UnB (Barros, 1998). Não há evidências de que o termo linha de pesquisa seja mera tradução de expressão consagrada na tradição de uma dessas influências. Como curiosidade, vale lembrar que a expressão linha teórica teve uso intenso há algumas décadas no âmbito da atividade acadêmica (o mesmo poderia ser dito da expressão corrente teórica). Não é de todo desprezível 
a possibilidade de que tal uso possa ter favorecido a consolidação do uso de linha de pesquisa. Talvez não estejamos falando de corrente (em vez de linha) de pesquisa por mero acaso; aliás, trata-se de expressão bastante sugestiva quanto à idéia de movimento em leito, cujo rumo não é invariável, idéia que talvez seja compatível com a noção de linha de pesquisa.

Diante de tal quadro ocorreu-me que poderia ser revelador examinar o texto do I Plano Nacional de Pós-Graduação, publicado em 1975, no Governo do General Ernesto Geisel, quando era Ministro da Educação Ney Braga (I PNPG, 1998). Como tal documento foi produzido em época na qual já estavam em funcionamento diversos Programas de Pós-Graduação nos moldes dos que existem hoje, e inclui dados e considerações sobre tais Programas, poderia conter algumas pistas interessantes sobre usos da expressão linhas de pesquisa. A garimpagem no longo documento resultou em alguns achados interessantes, transcritos a seguir.

A) "As atividades científicas compreendem a organização de linhas regulares de projetos de pesquisa, a produção de trabalhos profissionais de comunicação, discussão e intercâmbio de informações e temas culturais, científicos, técnicos, que são realizados por grupos” (I PNPG, 1998, p. 22, sem grifo no original).

B) "É conveniente que sejam designados, durante todas as fases do curso, orientadores acadêmicos individuais para acompanhar de perto o trabalho de cada aluno; e que os vários orientadores sejam coordenados ao nível do curso e departamentos para um melhor desempenho conjunto das linhas de trabalho e pesquisa” (I PNPG, 1998, p. 23, sem grifo no original).

C) “É conveniente que se coloque maior ênfase no uso de laboratórios e escritórios de projetos para atividades conjuntas de graduação e pós-graduação, cuidando da metodologia científica envolvida, e do engajamento progressivo de equipes de alunos, professores e pesquisadores em linhas de pesquisa de mais longo prazo” (I PNPG, 1998, p. 24, sem grifo no original).

D) “A organização do conhecimento humano e as estruturas das linhas de pesquisa e dos métodos educacionais definem, para a universidade, uma matriz de interdependência entre as áreas básicas, comuns a grandes ramos do conhecimento e a todas as linhas de trabalho científico, e áreas profissionais” (I PNPG, 1998, p. 30, itálicos no original, sem grifos no original). 
E) “A instituição que oferece o curso de mestrado e doutorado deve apresentar, por ocasião dos contatos pessoais com os candidatos, as informações sobre suas linhas curriculares e projetos de pesquisa em andamento e em preparo; com isto é possível elaborar, em conjunto com os candidatos, planos de trabalho na forma de um compromisso recíproco, flexível e responsável” (I PNPG, 1998, p. 23, sem grifos no original).

F) “Como as atividades de trabalho docente e de pesquisa são tipicamente de grupos, a diversidade de aptidões deve contribuir para uma melhor articulação das equipes, e não para a sua separação” (I PNPG, 1998, p. 24).

G) "Para que o planejamento seja eficaz, considera-se essencial que estas próprias diretrizes sejam interpretadas com a flexibilidade necessária para, ao mesmo tempo, corrigir distorções e consolidar o sistema” (I PNPG, 1998, p. 29).

O primeiro comentário a fazer é inevitável: o termo linha de pesquisa está presente no documento, com algumas variações. Tal constatação não é de todo surpreendente, pois em alguns Programas de Pós-Graduação pioneiros na área de Psicologia, sobrevivem ativas linhas de pesquisa que datam de 1970. O fato do termo linha de pesquisa estar presente no documento não significa, entretanto, que ele seja usado com definição precisa - e essa imprecisão é um dos pontos do qual parte o texto do Professor Jairo. No I PNPG fala-se em linhas de projetos de pesquisa, em linhas de trabalho e pesquisa, e em linhas de trabalho científico. Em outro ponto há menção a linhas curriculares e projetos de pesquisa. Mesmo falando de algo cuja definição não é detalhada, aparecem detalhes como estruturas das linhas de pesquisa, além de linhas de pesquisa de mais longo prazo.

Não tenho a pretensão de discutir aqui possíveis significados de tais fragmentos (nem sei se é possível fazê-lo), mas apenas registrá-los como adendos, que podem ter interesse para o texto que suscitou a presente réplica.

O Professor Jairo acredita que uma força impulsionadora do uso da expressão linha de pesquisa a partir da segunda metade da década de 80 , foi o reconhecimento de que o processo contemporâneo de pesquisa deve ser coletivo e articulado institucionalmente. É interessante verificar que o I PNPG já registrava a mesma compreensão, tal como se pode perceber na transcrição do trecho $\mathrm{F}$. Vale lembrar ainda que a institucionalização da pós-graduação é uma das diretrizes fundamentais do citado I PNPG.

O texto do Professor Jairo encampa a idéia de que um dos interesses principais da especificação de linhas de pesquisa deve ser o compromisso com a informa- 
ção. Mais uma vez é interessante verificar, na transcrição do trecho E, que a mesma preocupação está claramente expressada.

O Professor Jairo destaca a idéia de linha de pesquisa ser um termo "frouxo", propositadamente "frouxo". Percebo na transcrição do trecho G essa mesma lógica. É desse ponto que o Professor Jairo parte para construir a interessante proposta que arremata o seu texto. Ele utiliza, de início, o conceito de traço imaginário, que associa de modo combinatório vários elementos: determinação do rumo da investigação ou do que será investigado num dado contexto ou realidade; delimitação das fronteiras do campo específico do conhecimento em que está inserida a pesquisa; demarcação de orientação teórica; e estabelecimento de procedimentos adequados do ponto de vista metodológico.

Tais elementos permitem situar o conceito de linha de pesquisa em um ponto intermediário, na articulação com os conceitos de área de concentração e de projeto de pesquisa. Vejo a solução proposta como bastante criativa e promissora. Ainda assim registro um ponto para ser discutido: penso que o conceito de área de concentração também padece de “frouxidão”. Isso torna difícil considerálo como algo que não se confunde, de forma alguma, com o conceito de linha de pesquisa. Em outras palavras, tenho dúvidas quanto à possibilidade de uma afirmação do Professor Jairo aplicar-se a todos os casos. Trata-se da afirmação "parece que o conceito de área de concentração admite parte das atribuições de linhas de pesquisa: sempre limita as fronteiras do espaço, mas nunca estabelece, simultaneamente, os rumos da pesquisa, a orientação teórica e os procedimentos". Penso que o "nunca" pode ser desmentido, pelo menos quando considero a realidade da área da Psicologia (e tenho razões para acreditar que em diversas outras áreas a situação seja equivalente).

Proponho, para discussão, um esquema que considero mais ajustado à realidade, e que pode auxiliar a tarefa prática de explicitar (e identificar) linhas de pesquisa, embora não apresente uma solução para a caracterização do conceito. O modelo aparece abaixo.

\begin{tabular}{|l|c|c|c|}
\hline & $\begin{array}{c}\text { Área de } \\
\text { Concentração }\end{array}$ & $\begin{array}{c}\text { Linha de } \\
\text { Pesquisa }\end{array}$ & $\begin{array}{c}\text { Projeto de } \\
\text { Pesquisa }\end{array}$ \\
\hline $\begin{array}{l}\text { Delimita fronteiras do campo de } \\
\text { conhecimento da investigação }\end{array}$ & SEMPRE & SEMPRE & Não se aplica \\
\hline $\begin{array}{l}\text { Determina o rumo ou o que será } \\
\text { investigado num dado contexto }\end{array}$ & ÀS VEZES & SEMPRE & SEMPRE \\
\hline $\begin{array}{l}\text { Demarca orientação teórica, que } \\
\text { serve de referencial }\end{array}$ & ÀS VEZES & ÀS VEZES & SEMPRE \\
\hline $\begin{array}{l}\text { Estabelece procedimentos adequados } \\
\text { à investigação }\end{array}$ & ÀS VEZES & ÀS VEZES & SEMPRE \\
\hline
\end{tabular}


O modelo acima deve ser entendido como uma provocação à discussão. Perceba-se que a idéia de "frouxidão progressiva", proposta no texto do Professor Jairo, foi inteiramente aproveitada.

Do ponto de vista prático relacionado à avaliação de Programas de PósGraduação, cobra-se coerência entre área de concentração, linhas e projetos de pesquisa. O texto do Professor Jairo mostra como a aferição do cumprimento de tal exigência pode ser difícil e sujeita às idiossincrasias dos avaliadores, o que é muito perigoso. A discussão que envolve a primazia de Programas mais fechados em torno de uma área de concentração estreitada, à qual correspondam linhas de pesquisa que representem algumas das facetas da temática em questão, na comparação com Programas que apostam em maior diversidade de focos de atuação, com linhas de pesquisa que não guardem nexo evidente entre si, mesclase com a discussão da coerência. Carvalho (2001) apresenta a questão com muita clareza:

“como avaliar a conveniência de uma formação geral versus uma formação especializada, ou da heterogeneidade versus a homogeneidade temática em um programa de pós-graduação? A nosso ver, há critérios distintos cuja aplicação requer a consideração tanto de fatores contextuais como das especificidades da dinâmica interna dos programas. No limite, a heterogeneidade temática pode representar incoerência ou descontinuidade na formação; no entanto, pode também representar abertura para novos temas e enfoques, desde que esteja escorada em uma postura epistemológica coerente. Por sua vez, a homogeneidade pode se refletir em uma produção mais rápida, mas também mais focalizada e menos inovadora”.

Como proposta para discussão é possível mencionar que, considerando o fato de que um mesmo docente/pesquisador pode estar associado a mais de uma linha de pesquisa, e considerando as vantagens para o desenvolvimento do Programa e para a formação pós-graduada que podem resultar do intercâmbio e da cooperação entre todos os pesquisadores (e deles com pesquisadores de outros Programas), a estratégia de extrema pulverização ou de aposta no individualismo deve ser sempre vista como a menos desejável. 


\section{ReferênCias Bibliográficas}

BARROS, E. M. C.

Política de pós-graduação: um estudo da participação da comunidade científica. São Carlos: EdUFSCar, 1998.

CARVALHO, A. M. A.

Monitoramento e avaliação da pósgraduação: algumas reflexões sobre requisitos e critérios. Psicologia USP, v. 12, n. 1, p. 203221, 2001. Disponível em: <http:// www.scielo.br> Acesso em: 2003.

I PNPG.

I Plano Nacional de Pós-Graduação: 1975. Infocapes/ Boletim Informativo da Capes, v. 6, n. 1, p. 12-50, 1998. 